\title{
Correction to: Adolescent Coordinated Transition (ACT) to improve health outcomes among young people living with HIV in Nigeria: study protocol for a randomized controlled trial
}

Nadia A. Sam-Agudu ${ }^{1,2}$, Jennifer R. Pharr ${ }^{3}$, Tamara Bruno ${ }^{3}$, Chad L. Cross ${ }^{4}$, Llewellyn J. Cornelius ${ }^{5}$, Prosper Okonkwo ${ }^{6}$, Bolanle Oyeledun ${ }^{7}$, Hadiza Khamofu', Ayodotun Olutola ${ }^{9}$, Salome Erekaha ${ }^{1}$, William Nii Ayitey Menson ${ }^{3}$ and Echezona E. Ezeanolue ${ }^{3^{*}}$

\section{Correction}

In the original publication [1] the figure captions of Figs. 2 and 3 were reversed. The correct version can be found in this Erratum.

Incorrect version Fig. 2:

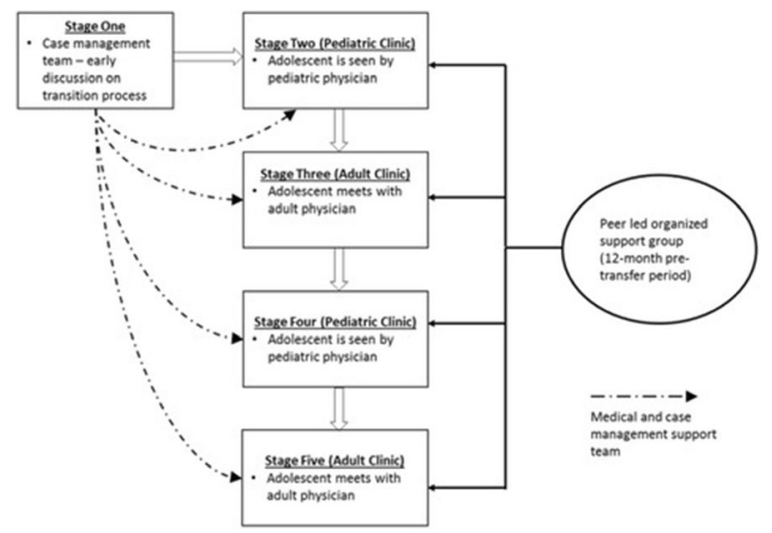

Fig. 2 Consolidated Standards of Reporting Trials (CONSORT) flow diagram for Adolescent Coordinated Transition (ACT) trial site selection
Correct version Fig. 2:

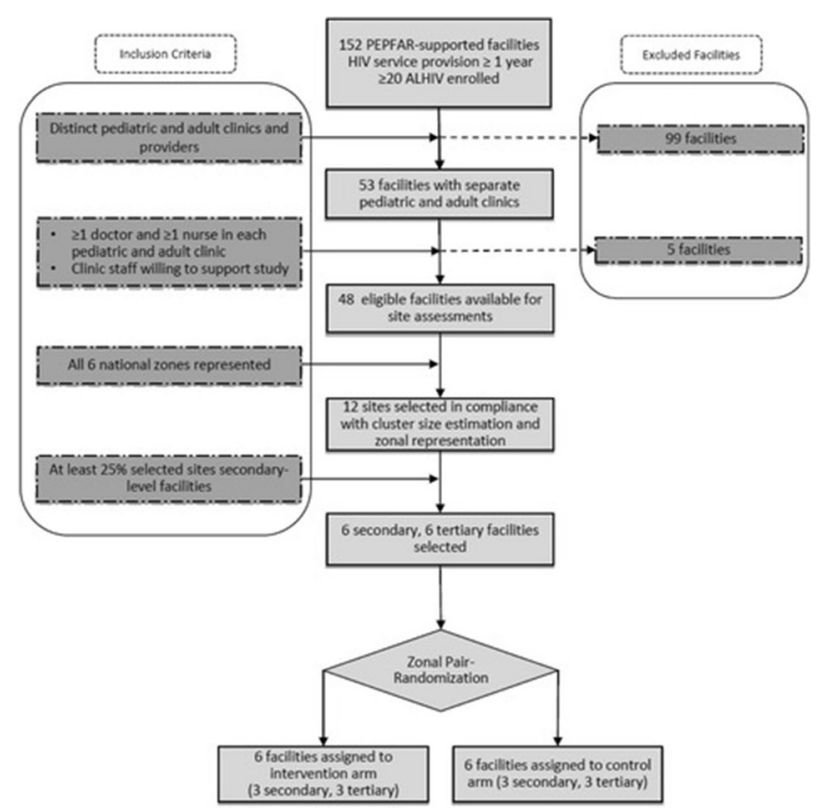

Fig. 2 Adolescent Coordinated Transition (ACT) transitioning model showing the 12-month pre-transfer period (adapted from Maturo et al. [19])

\footnotetext{
*Correspondence: eezeanolue@gmail.com; echezona.ezeanolue@gmail.com ${ }^{3} \mathrm{Global}$ Health Initiative, School of Community Health Sciences, University of Nevada Las Vegas, 4505 S. Maryland Parkway, Las Vegas, NV 89154, USA

Full list of author information is available at the end of the article
} 


\section{Incorrect version Fig. 3:}

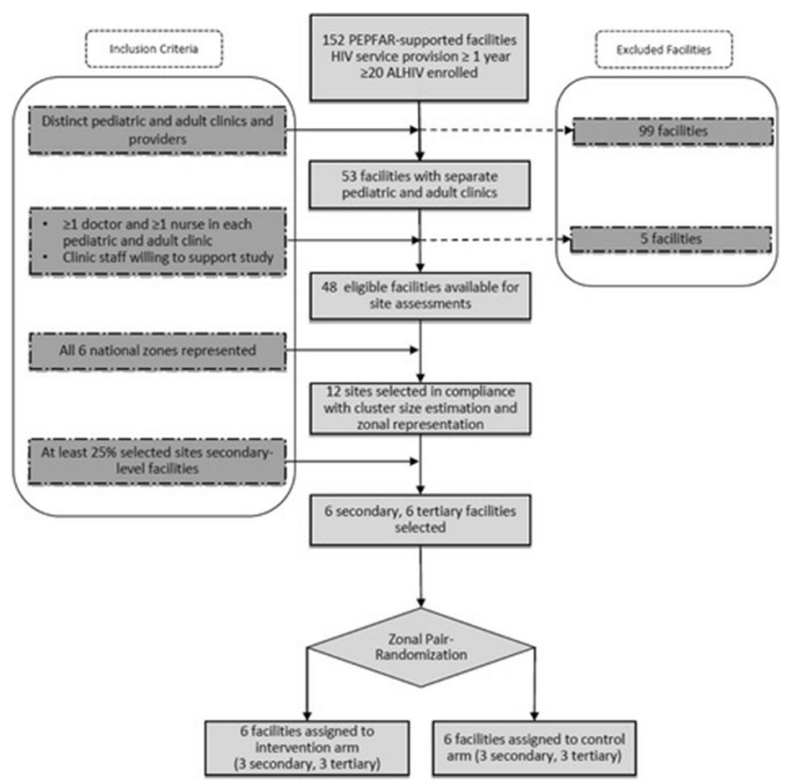

Fig. 3 Adolescent Coordinated Transition (ACT) transitioning model showing the 12-month pre-transfer period (adapted from Maturo et al. [19])

\section{Correct version of Fig. 3:}

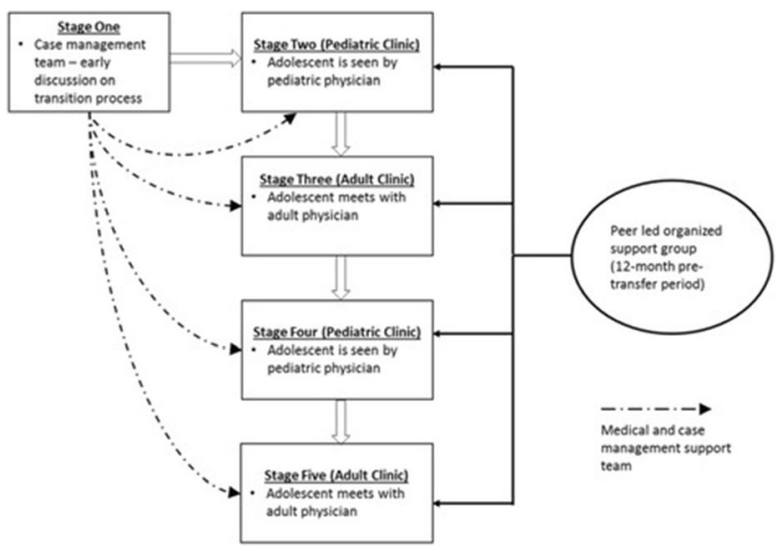

Fig. 3 Consolidated Standards of Reporting Trials (CONSORT) flow diagram for Adolescent Coordinated Transition (ACT) trial site selection

\section{Author details}

${ }^{1}$ Pediatric and Adolescent HIV Unit, Clinical Services, and International Research Center of Excellence, Institute of Human Virology Nigeria, Abuja, Nigeria. ${ }^{2}$ Division of Epidemiology and Prevention, Institute of Human Virology, University of Maryland School of Medicine, Baltimore, OH, USA. ${ }^{3}$ Global Health Initiative, School of Community Health Sciences, University of Nevada Las Vegas, 4505 S. Maryland Parkway, Las Vegas, NV 89154, USA. ${ }^{4}$ School of Medicine and School of Community Health Sciences, University of Nevada, Las Vegas, NV, USA. ${ }^{5}$ School of Social Work and College of Public Health, University of Georgia Athens, Athens, GA, USA. ${ }^{6}$ APIN Public Health Initiatives, Abuja, Nigeria. ${ }^{7}$ Centre for Integrated Health Programs, Abuja, Nigeria. ${ }^{8} \mathrm{FHI}$ 360, Abuja, Nigeria. ${ }^{9} \mathrm{C}$ enter for Clinical Care and Clinical Research Nigeria, Abuja, Nigeria.
Published online: 13 February 2018

\section{Reference}

1. Sam-Agudu NA. Adolescent Coordinated Transition (ACT) to improve health outcomes among young people living with HIV in Nigeria: study protocol for a randomized controlled trial. Trials. 2017;18:595. https://doi.org/10.1186/ s13063-017-2347-z
Submit your next manuscript to BioMed Central and we will help you at every step:

- We accept pre-submission inquiries

- Our selector tool helps you to find the most relevant journal

- We provide round the clock customer support

- Convenient online submission

- Thorough peer review

- Inclusion in PubMed and all major indexing services

- Maximum visibility for your research

Submit your manuscript at www.biomedcentral.com/submit
Biomed Central 